\title{
Pengaruh Pasang Surut terhadap Pengendapan Lumpur di Lahan Sawah Rawa Kawasan Sungai Barito Kalimantan Selatan
}

Effects of The Tides on The Mud Clay Deposition in The Wetland Rice Field of Tidal Swamps of Barito River of South Kalimantan

\section{Mawardi1,2*, Putu Sudira ${ }^{3}$, Bambang Hendro Sunarminto ${ }^{1}$, Totok Gunawan 4 Benito Hadi Purwanto ${ }^{1}$}

'Departemen Ilmu Tanah, Fakultas Pertanian, Universitas Gadjah Mada, Jl. Flora, Bulaksumur, Yogyakarta 55281, Indonesia

${ }^{2}$ Balai Penelitian Pertanian Lahan Rawa, Jl. Kebun Karet PO Box 31 Banjarbaru, Kalimantan Selatan 70712, Indonesia ${ }^{3}$ Departemen Teknik Pertanian dan Biosistem, Fakultas Teknologi Pertanian, Universitas Gadjah Mada, Jl. Flora No. 1, Bulaksumur, Yogyakarta 55281, Indonesia

${ }^{4}$ Fakultas Geografi, Universitas Gadjah Mada, Jl. Kaliurang, Sekip Utara, Bulaksumur, Yogyakarta 55281, Indonesia *Email: balittra@litbang.pertanian.go.id

Tanggal submisi: 12 Maret 2018; Tanggal penerimaan: 24 Juli 2018

\begin{abstract}
ABSTRAK
Lahan rawa sangat berpotensi untuk dikembangkan sebagai area tanaman padi, namun banyak kendala seperti adanya lapisan pirit $\left(\mathrm{FeS}_{2}\right.$ ) pada kedalaman 30-60 cm dan miskin unsur hara. Adanya suplai lempung marin dari lumpur laut melalui proses pasang surut yang mengandung cukup mineral lempung smektit yang jenuh basa-basa dapat menetralisir sifat asam akibat pirit. Selain itu lumpur sangat penting untuk perakaran padi, mengandung unsur hara dan mempertebal lapisan atas agar lapisan pirit tidak teroksidasi. Penelitian ini dilaksanakan dari Bulan November 2015 sampai Bualan Juni 2017 di area persawahan pasang surut kawasan Sungai Barito Kalimantan Selatan. Penelitian ini merupakan penelitian lapangan, dengan mengamati selisih antara pasang maksimum dan surut maksimum (amplitudo pasang surut) dan pengamatan endapan lumpur. Hasil penelitian menunjukkan sebaran lumpur antar zona berbeda-beda tergantung kondisi geografi dan amplitudo pasang surut di zona tersebut. Zona VII memiliki kadar lumpur lebih tinggi dibandingkan zona lainya, pola sebaran lumpur mengikuti pola parabola (kuadratik) baik secara vertikal mau pun horizontal. Amplitudo pasang surut harian tidak berpengaruh terlalu besar terhadap peningkatan kadar lumpur pada semua zona dan hanya tergantung kepada musim.
\end{abstract}

Kata kunci: Lumpur; pirit; pasang surut; lahan sawah pasang surut

\begin{abstract}
Swamp land has a great potential to be developed as a paddy field area. However it has many constraints such as-phyrite $\left(\mathrm{FeS}_{2}\right)$ at the depth of 30-60 cm and lack of soil nutrition. On the other hand, supply of marine clay from the sea which contains a lot of smektit clay mineral can be used to netralize this condition. Mud clay is very important for the development of rice root because it contains much nutrition and to enlarge the top of soil reducing the oxidation of phyrite. This study was conducted from January 2016 to June 2017 in swamp land area of Barito River of South Kalimantan. Data was collected by measuring the difference between maximum and minimum sea tide (tidal amplitude) and the deposition of mud clay. The results indicated that the distribution of mud clay deposit vary depends on the geography and the tidal amplitude of the zone. Zone VII has higher concenration of mud clay than the other one. The distribution pattern of mud clay deposit follows the parabola type, verticaly and horizontaly type, as well. Increasing of mud clay at all of the zone areas are not significantly effected by the daily tidal amplitude, only depends on climate condition/the season change.
\end{abstract}

Keywords: Mud clay; phyrite; tidal of the sea; tidal rice field 


\section{PENDAHULUAN}

Pasang surut terbentuk karena gaya tarik semua planet, terutama bulan dan matahari terhadap bumi (Franco, 1986). Tarikan itu akan menyebabkan badan air laut bergerak vertikal dan horizontal, sehingga permukaan air laut tidaklah statisk melainkan dinamik dan selalu bergerak (Marchuk dan Kagan, 1983). Untuk mengetahui karakteristik pasang surut laut, perlu dilakukan pengamatan di lapangan (Hydrographic Services, 1987), dengan menggunakan alat perekam pasang surut otomatis, rambu visual (Unesco, 1984) dan bisa juga dengan manual atau secara digital. Data ini kemudian dihitung agar karakteristik pasang surut laut dapat diketahui (Hydrographer of the Nurry, 1969) dan dianalisis pengaruhnya terhadap endapan lumpur di lahan.

Karakteristik pasang surut laut untuk suatu daerah berbeda antara satu daerah dengan daerah atau lokasi lainya. Pariwono (1985) mengelompokkan dua karakteristik pasang surut laut di Indonesia yaitu pasang surut tunggal mendominasi perairan Indonesia sebelah barat dan pasang surut ganda mendominasi perairan Indonesia sebelah timur.

Potensi lahan rawa lahan pasang surut di Indonesia yang cocok untuk usaha pertanian masih cukup luas. Sampai saat ini pemanfaatan lahan rawa sebagai usaha pertanian masih terbatas, sehingga peluang untuk meningkatkan peran lahan ini ke depan masih cukup besar sebagai sumber pertumbuhan pertanian, namun dalam mengelola lahan ini, diperlukan kehati-hatian karena adanya lapisan sulfida (Sudana, 2005).

Berbagai kegagalan dan keberhasilan telah mewarnai kegiatan pengembangan lahan rawa. Terjadinya lahan bongkor misalnya, yaitu lahan yang ditinggalkan petani karena telah mengalami oksidasi pirit sehingga produksinya sangat rendah, merupakan akibat dari reklamasi yang kurang tepat pada lahan sulfat masam (Suriadikarta, 2012).

Permasalahan ini terjadi akibat adanya lapisan pirit $\left(\mathrm{FeS}_{2}\right.$ ) pada kedalaman $30-60 \mathrm{~cm}$ dari permukaan tanah atas yang mengalami oksidasi terutama pada musim kemarau sehingga menimbulkan kemasaman tanah dan kelarutan Fe yang tinggi (Shamsuddin dkk., 2004) disamping rendahnya status unsur hara terutama unsur P. Namun, apabila tanah memiliki cukup besar senyawa-senyawa penetralisir, seperti ion $\mathrm{OH}-$, kapur $\left(\mathrm{CaCO}_{3}\right)$, basa-basa dapat tukar, dan mineral-mineral silikat mudah melapuk sehingga $\mathrm{pH}$ tanah tidak sampai turun di bawah 4,0. Adanya lempung marin yang mengandung cukup mineral lempung smektit yang jenuh basa-basa dapat menetralisirnya (Subagyo, 2006).
Lumpur di lahan menjadi sesuatu yang sangat penting selain untuk perakaran padi. Tanaman ini menghendaki tanah berlumpur yang subur dengan ketebalan $18-22 \mathrm{~cm}$. Lumpur berfungsi sebagai penyedia hara, memudahkan peranakan padi, apalagi di lahan rawa pasang surut dimana lumpur berasal dari luapan sungai yang berasal dari hulu yang banyak mengandung unsur hara.

Selain itu, di lahan rawa pasang surut sebagian lumpur berasal dari endapan marin yang dapat menyerap besi sehingga tidak meracuni tanaman. Bahkan dengan bertambahnya lumpur maka jeluk pirit semakin dalam dan semakin aman untuk pertanaman padi. Pada lahan pasang surut dengan tipologi sulfat masam, dimana lapisan piritnya relatif dangkal yakni kurang dari $50 \mathrm{~cm}$, pengolahan tanahnya harus minimum atau dangkal agar lapisan pirit tidak teroksidasi, yang mengakibatkan tanah menjadi masam. Sebaliknya, pada tipologi lahan potensial dengan kedalaman lapisan pirit lebih dari $50 \mathrm{~cm}$, pengolahan tanah bisa lebih dalam untuk memperluas areal perakaran tanaman, tetapi tidak sampai ke lapisan pirit (Sudana, 2005).

Pengelolaan tanah dan air (soil and water management) merupakan kunci utama keberhasilan pengembangan pertanian di lahan rawa pasang surut, termasuk tanah sulfat masam yang sesuai dengan kebutuhan tanaman (Suriadikarta, 2012). Menurut petani di lapangan jika terjadi banjir lumpur, hasil padi tahun tersebut akan meningkat. Selain itu, area sawah yang memiliki ketebalan lumpur setebal $20 \mathrm{~cm}$ sangat bagus untuk pertanaman padi di lahan pasang surut.

Peran lumpur ternyata sangat penting dalam menujang keberhasilan usaha tani padi di lahan pasang surut. Namun penelitian tentang lumpur itu sendiri dan distribusi spasialnya belum cukup banyak dilakukan. Oleh karena itu, penelitian lumpur dan hubunganya dengan pasang surut menjadi sangat penting dan perlu dilakukan sebagai sumber informasi dan direkomendasikan untuk usaha tani padi pasang surut.

\section{METODE PENELITIAN}

\section{Lokasi Penelitian}

Penelitian dilaksanakan pada bulan November 2015 sampai Juni 2017 di area persawahan seluas kurang lebih $650 \mathrm{~km}^{2}$. Area persawahan tersebut merupakan kawasan tepian sungai Barito Kalimantan Selatan yang memanjang dari muara laut sampai sejauh $60 \mathrm{~km}$ ke arah hulu dan melebar ke arah samping sekitar $10 \mathrm{~km}$, mengikuti saluran primer yang tegak lurus dengan Sungai Barito. Lokasi penelitian terletak pada $3^{\circ} 30^{\prime} 38^{\prime \prime} \mathrm{LS}-2^{\circ} 44^{\prime} 6^{\prime \prime} \mathrm{LS}$ dan $14^{\circ} 6^{\prime} 58^{\prime \prime} 244$ BT- $114^{\circ} 20^{\prime} 55^{\prime \prime}$. 


\section{Bahan dan Alat}

Pengamatan tinggi air di lapangan untuk menghitung amplitudo pasang surut menggunakan pengukur manual meteran kontrol air dari plastik (Gambar 1.a) dan water logger merk HOBO U 20-001 onset buatan Jepang (Gambar 1.b) Sedangkan alat untuk menampung (perangkap) lumpur di lahan digunakan wadah plastik berdiameter $50 \mathrm{~cm}$, tinggi $25 \mathrm{~cm}$ buatan Indonesia, yang dimodifikasi dengan melubangi wadah tersebut (Gambar 1.c). Timbangan digital $5.000 \mathrm{~g}$ model EK9350H merk Kris Chef buatan China digunakan untuk menimbang berat lumpur basah. Timbangan analitik 4 digit desimal max $110 \mathrm{~g}$ model AR1140/ohaus buatan USA digunakan mengukur berat lumpur kering mutlak. Oven merk eijkelkamp buatan Belanda untuk mengoven lumpur suhu $110^{\circ} \mathrm{C}$ untuk mendapatkan kering mutlak. Pipa paralon 3 inc digunakan untuk melindungi water logger di lapangan (Gambar 1.C), dan GPS merk Gamin model MAP $78 S$ buatan USA digunakan untuk mengetahui dan merekam koordinat.

\section{Analisis Data}

Penelitian ini menggunakan peta amplitudo pasang surut $(\Delta)$ yang dibuat berdasarkan pengukuran pasang maksimum dan surut maksimum selama 24 jam (Gambar 2) di saluran primer. Berdasarkan nilai amplitudo pasang surut $(\Delta)$ tersebut, kemudian dideleniasi untuk menghasilkan peta amplitudo pasang surut $(\Delta)$ secara horizontal dan vertikal. Sketsa ilustrasi ditampilkan pada Gambar 3.

Peta amplitudo pasang surut $(\Delta)$ secara horizontal yaitu: sejajar dengan laut, dari muara Sungai Barito ke arah hulu (Gambar 4). Berdasarkan nilai selisih antara pasang maksimum dan surut maksimum ( $\Delta$ amplitudo pasang surut) dari muara ke arah hulu sejauh $60 \mathrm{~km}$, kemudian dibagi 4 zona yaitu: zona I, area $\Delta>200 \mathrm{~cm}$ ), zona II, $\Delta(150-200 \mathrm{~cm})$, zona III $\quad(150-100 \mathrm{~cm}$ dan zona IV $(<100 \mathrm{~cm})$. Peta amplitudo pasang surut vertikal yaitu: tegak lurus dengan laut, dari muara saluran primer (yang behubungan langsung dengan Sungai Barito) ke arah dalam saluran (Gambar 5) berdasarkan selisih antara pasang maksimum dan surut maksimum ( ) dari muara saluran primer ke arah dalam sampai ujung sekitar $10 \mathrm{~km}$, dibagi 4 zona juga yaitu zona I, $>120 \mathrm{~cm})$, zona II, $(120-100 \mathrm{~cm})$, zona III, (100$80 \mathrm{~cm}$ dan zona IV, $(<80 \mathrm{~cm})$.

Dari 4 zona $\Delta$ pasang surut secara horizontal dan 4 zona secara vertikal ditumpang tepat (overlay) dan seleksi berdasarkan daerah yang masih dapat terluapi pasang surut secara maksimal dan ditetapkan menjadi 9 zona (Gambar 6). Pengamatan endapan lumpur dilakukan dengan cara menampung endapan lumpur yang terbawa pada saat air pasang dan mengendap (tertinggal) pada saat surut di dalam bak kontrol lumpur berdiameter $50 \mathrm{~cm}$ dan tinggi $25 \mathrm{~cm}$ (Gambar 1.c). Lumpur yang diperoleh di lapangan dibersihkan dari sampah-sampah yang masuk, disaring, ditimbang kemudian dioven selama 24 jam dengan suhu $105^{\circ} \mathrm{C}$ untuk mendapatkan kering mutlak. Lumpur yang sudah kering mutlak ditimbang beratnya dengan timbangan digital.

Pengamatan dilakukan pada 9 zona area penelitian tersebut sebanyak tiga titik pengamatan sehingga berjumlah menjadi 27 titik pengamatan. Sedangkan untuk pengamatan pasang surut air, dipasang alat water logger (Gambar 1.b) di dua titik yaitu: di hilir dekat dengan muara laut (3 km dari laut) di kecamatan Tabungenen dan di hulu batas akhir area penelitian di Kecamatan Barambai sejauh $60 \mathrm{~km}$ dari muara laut (water logger hilir). Logger ini diset mencatat secara otomatis setiap jam selama penelitian (6 bulan) yaitu dari bulan Januari sampai Juni 2017. Data Hasil pencatatan alat diolah untuk mendapatkan rata-rata $(\Delta)$ pasang surutnya setiap hari dan setiap bulan.

Data hasil pengamatan lumpur di lapangan ditabulasi, diolah untuk mendapatkan rata-rata per

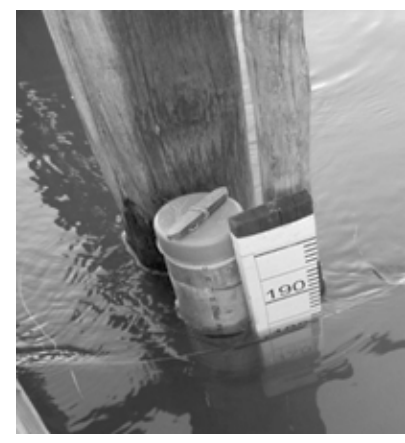

(a)

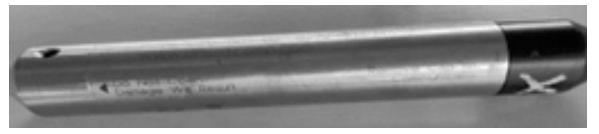

(b)

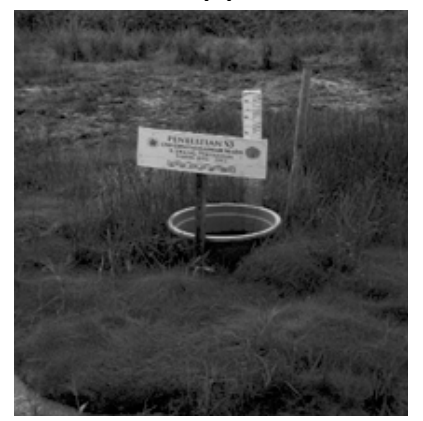

(c)

Gambar 1. Alat pengukur kadar lumpur (a) dan water logger, (b) meteran manual dan digital dipasang berdampingan untuk mengukur tinggi air (c) 
bulan meter persegi jumlah lumpur yang diperoleh. Selanjutnya dianalisis dan dideskripsikan dengan diagram batang dan bandingkan untuk melihat perbedaan berat endapan lumpur di tiap tiap zona lokasi (9 zona) dan sebarannya. Untuk melihat pengaruh atau hubungan antara endapan lumpur dengan $\Delta$ pasang surut dilakukan analisis korelasi.

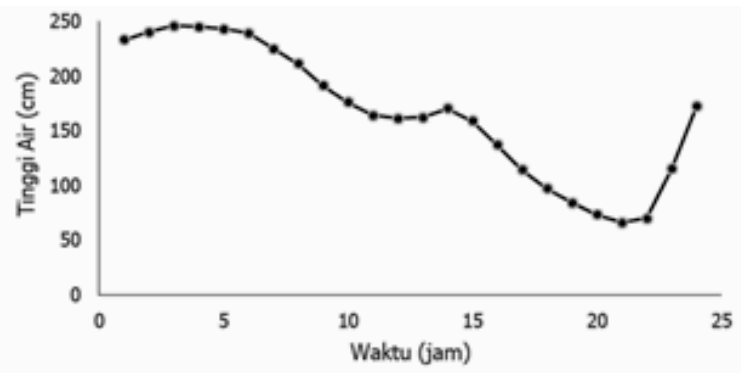

Keterangan: Amplitudo $(\Delta)$ pasang surut adalah pasang maksimum $246 \mathrm{~cm}$ dan minimumnya $66 \mathrm{~cm}$ sehingga amplitodunya $180 \mathrm{~cm}$

Gambar 2. Pengukuran tinggi air untuk menghitung amplitudo $(\Delta)$ pasang surut pada salah salah titik pengamatan di daerah Jelafa Muara setiap zona baik vertikal maupun horizontal

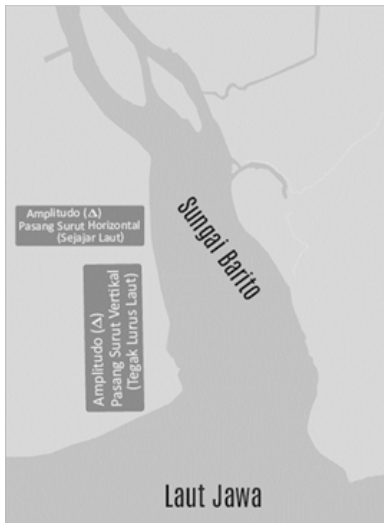

Gambar 3. Sketsa ilustrasi zonasi amplitudo $(\Delta)$ pasang surut secara vertikal dan horizontal

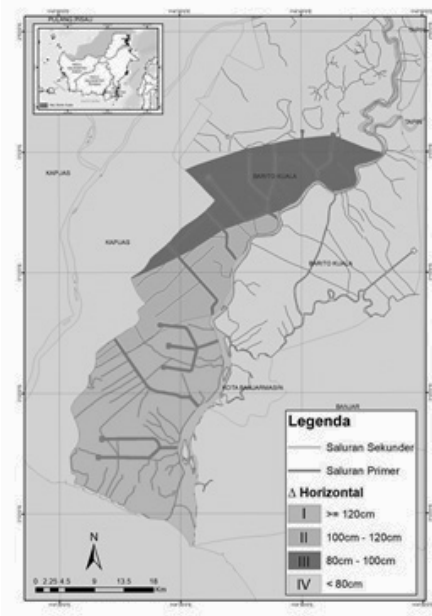

Gambar 4. Zona amplitodu $(\Delta)$ pasang surut secara horizontal dari muara sungai ke arah hulu Sungai Barito

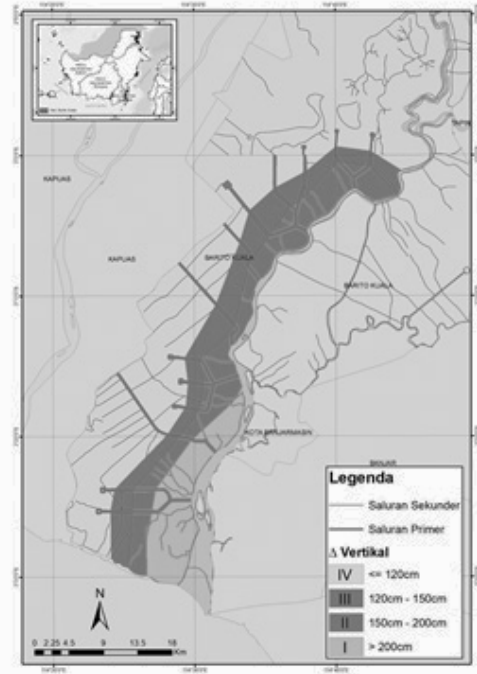

Gambar 5. Zona $\Delta$ pasang surut secara vertikal dari muara sungai ke arah hulu Sungai Barito

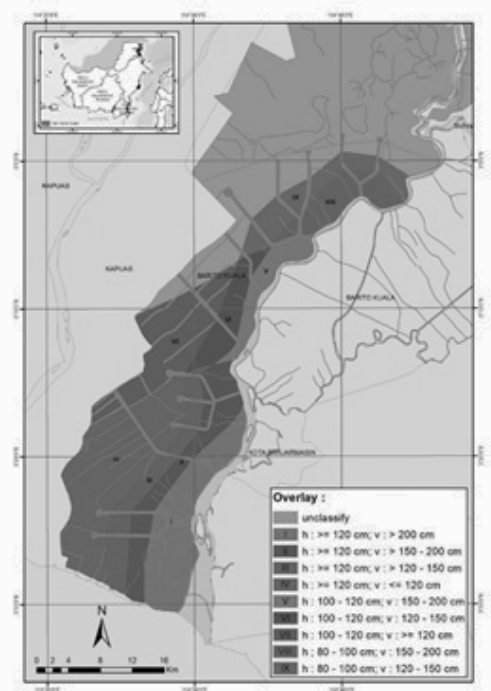

Gambar 6. Zona pengamatan lumpur di lahan sawah kawasan Sungai Barito

\section{HASIL DAN PEMBAHASAN}

Hasil pengamatan rata rata endapan lumpur perbulan selama 6 bulan pada 9 zona pengamatan titik sampel lumpur ditampilkan pada Tabel .1

\section{Sebaran Lumpur Antar Zona}

Dari Tabel 1 sebaran lumpur berkisar rata rata 43,1 $\mathrm{g} / \mathrm{m}^{2} /$ bulan sampai $64,1 \mathrm{~g} / \mathrm{m}^{2} /$ bulan atau 258,5 sampai $384,8 \mathrm{~g} / \mathrm{m}^{2} / 6$ bulan. Selama musim hujan, kecuali zona VII yang sangat berbeda dengan zona lainnya, yaitu $757,9 \mathrm{~g} / \mathrm{m}^{2} /$ bulan atau rata rata $126,3 \mathrm{~g} / \mathrm{m}^{2} /$ bulan, jauh lebih tinggi dibandingkan dengan zona lainya. Kondisi ini disebabkan oleh beberapa faktor. Contohnya zona $\Delta$ pasang surut berada pada area $\Delta$ pasang surut horizontal $100-120 \mathrm{~cm}$ dan vertikal $>120 \mathrm{~cm}$ dengan 
Tabel 1. Hasil pengamatan lumpur pada 9 zona selama 6 bulan di lahan rawa pasang surut

\begin{tabular}{|c|c|c|c|c|c|c|c|c|c|c|c|}
\hline Bulan & $\begin{array}{c}\text { Zona I } \\
\left(\mathrm{g} / \mathrm{m}^{2} / \mathrm{bln}\right)\end{array}$ & $\begin{array}{c}\text { Zona II } \\
\left(\mathrm{g} / \mathrm{m}^{2} / \mathrm{bln}\right)\end{array}$ & $\begin{array}{c}\text { Zona } \\
\left(\mathrm{g} / \mathrm{m}^{2} / \mathrm{bln}\right)\end{array}$ & $\begin{array}{c}\text { Zona IV } \\
\left(\mathrm{g} / \mathrm{m}^{2} / \mathrm{bln}\right)\end{array}$ & $\begin{array}{c}\text { Zona V } \\
\text { (g/m²/bln) }\end{array}$ & $\begin{array}{l}\text { Zona VI } \\
\left(\mathrm{g} / \mathrm{m}^{2} / \mathrm{bln}\right)\end{array}$ & $\begin{array}{l}\text { Zona VII } \\
\left(\mathrm{g} / \mathrm{m}^{2} / \mathrm{bln}\right)\end{array}$ & $\begin{array}{l}\text { Zona VIII } \\
\left(\mathrm{g} / \mathrm{m}^{2} / \mathrm{bln}\right)\end{array}$ & $\begin{array}{c}\text { Zona IX } \\
\text { (g/m²/bln) }\end{array}$ & $\begin{array}{c}\text { Total } \\
\left(\mathrm{g} / \mathrm{m}^{2} / \mathrm{bln}\right)\end{array}$ & SD \\
\hline Januari & 154,6 & 182,9 & 119,2 & 108,7 & 163,3 & 142,4 & 376,8 & 75,8 & 44,2 & 1367,9 & 94,9 \\
\hline Pebruari & 88,1 & 105,9 & 161,0 & 112,4 & 117,2 & 179,9 & 325,5 & 282,3 & 281,4 & 1653,8 & 89,9 \\
\hline Maret & 3,2 & 5,2 & 2,4 & 3,3 & 1,8 & 4,8 & 27,8 & 3,0 & 4,3 & 55,6 & 8,2 \\
\hline April & 5,6 & 7,1 & 4,4 & 4,9 & 3,0 & 8,1 & 19,7 & 10,6 & 3,8 & 67,3 & 5,2 \\
\hline Mei & 4,6 & 4,3 & 3,8 & 3,5 & 6,5 & 7,2 & 6,1 & 11,3 & 4,1 & 51,4 & 2,5 \\
\hline Juni & 2,3 & 1,6 & 3,6 & 2,0 & 5,1 & 2,8 & 2,1 & 1,9 & 2,0 & 23,5 & 1,1 \\
\hline Total & 258,5 & 307,0 & 294,5 & 234,8 & 296,9 & 345,2 & 757,9 & 384,8 & 339,8 & 3219,4 & 156,8 \\
\hline Rata-rata & 43,1 & 51,2 & 49,1 & 39,1 & 49,5 & 57.5 & 126.3 & 64.1 & 56.6 & 536.6 & 26,1 \\
\hline
\end{tabular}

perbedaan pasang tertinggi dan pasang terendah dengan arus yang kuat, yang kemudian mempengaruhi total suspensi sedimen yang terbawa air dan akhirnya berpengaruh terhadap proses sedimentasi (Hariyanto dkk., 2017) di lahan sawah zona VII tersebut. Selain itu, faktor geografis juga sangat mempengaruhi proses sedimentasi seperti yang terjadi di Sungai Mekong terbetuknya delta yang merupakan hasil endapan sungai dipengaruhi beberapa faktor seperti curah hujan, temperatur, dan karakteristik geografi (Thuy \& Anh, 2015).

Karakteristik Sungai Barito yang berbentuk meander dan posisi saluran primer di Kecamatan Anjir (VII) tersebut berhadapan dengan arus balik Sungai Barito yang sangat mendukung terjadinya pengendapan lumpur lebih banyak pada zona tersebut. Air yang membawa lumpur lebih besar masuk ke saluran primer, dari saluran primer, masuk ke saluran sekunder dan terus suspensi mengalir ke sawah pada zona VII tersebut. Selain itu pada zona VII merupakan titik di saluran primer betemunya dua arus yang berasal dari Sungai Barito dari utara dan Sungai Kapus arah Selatan. Akibat pertemuan dua arus inilah pada saat pasang yang menyebabkan banyak suspensi yang endapkan pada zona VII. Besarnya pengendapan di zona VII memungkinkan padi dapat tumbuh dengan baik. Dengan demikian zona VII berpotensi menjadi area penghasil padi terbesar di kabupaten Barito Kuala sejak tahun 2011- 2015 yaitu: 34.234, 32.409, 27.205, dan 30.431 ton thn ${ }^{-1}$ (BPS, 2017).

Sebaran lumpur juga dipengaruhi oleh musim. Dari 9 zona, hanya bulan Januari dan Februari yang kadar lumpurnya sangat tinggi sedangkan pada bulanbulan lainnya terus menurun seperti tersaji pada Gambar 7. Hal ini diduga kuat bahwa endapan lumpur dipengaruhi oleh banyak suspensi yang terbawa air pada saat awal musim hujan. Endapan ini berasal dari hasil erosi di daerah hulu yang terbawa aliran ke sungai sekitarnya dan berakhir di sungai Barito. Sesuai sejarah terbentuknya lahan rawa pasang surut (delta)

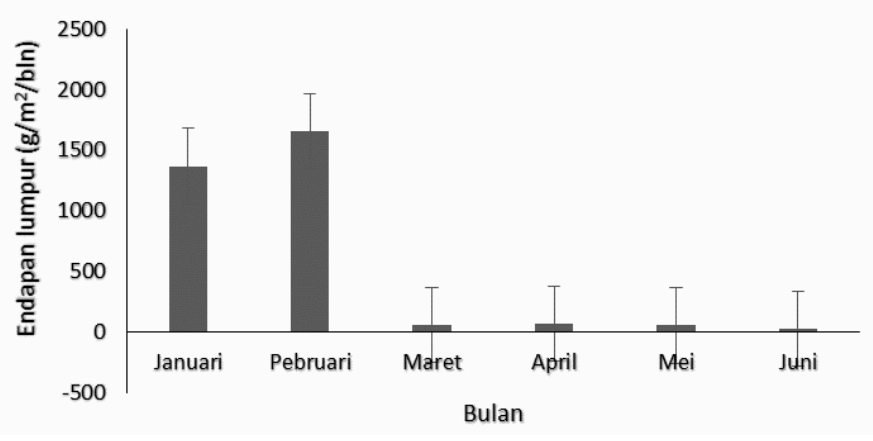

Gambar 7. Total endapan lumpur pada semua zona pengamatan setiap bulan di kawasan Sungai Barito

berasal dari Ayunan pasang surut dari laut dan sungai di sekitarnya disertai dengan pengelontoran tanah oleh air (erosi), membentuk endapan baru berupa daratan lahan rawa pasang surut (Noor, 2004).

Pada bulan Maret, April, Mei, dan Juni, endapan lumpur terus menurun yang diduga kuat pada bulan tersebut supensi yang terbawa air berkurang sehinga yang terendapkan di sawah juga sedikit. Air yang mengandung lumpur diendapkan di petak sawah pada lapisan olah. Kualitas dan jumlah lumpur yang diendapkan sangat beragam, tergantung dari sumber lumpur dan jumlah aliran (Hardjowigeno, 2004). Pada bulan Juni lumpur yang diendapkan sudah sangat sedikit, karena pada saat ini sudah memasuki awal musim kemarau. Meskipun terjadi pasang, dorongan air dari Sungai Barito tidak kuat sehingga dibeberapa zona tidak terluapi air terutama pada saat pasang kecil.

\section{Pengaruh Nilai Amplitudo Pasang Surut ( $\Delta)$ terhadap Sebaran Lumpur}

Sebaran endapan lumpur sangat dipengaruhi pasang surut air karena air sebagai media transpotasi lumpur. Korelasi zona $\Delta$ pasang surut (nilai amplitudo) secara vertikal selama 6 bulan pengamatan diilustrasikan pada Gambar 8. Berdasarkan diagram 

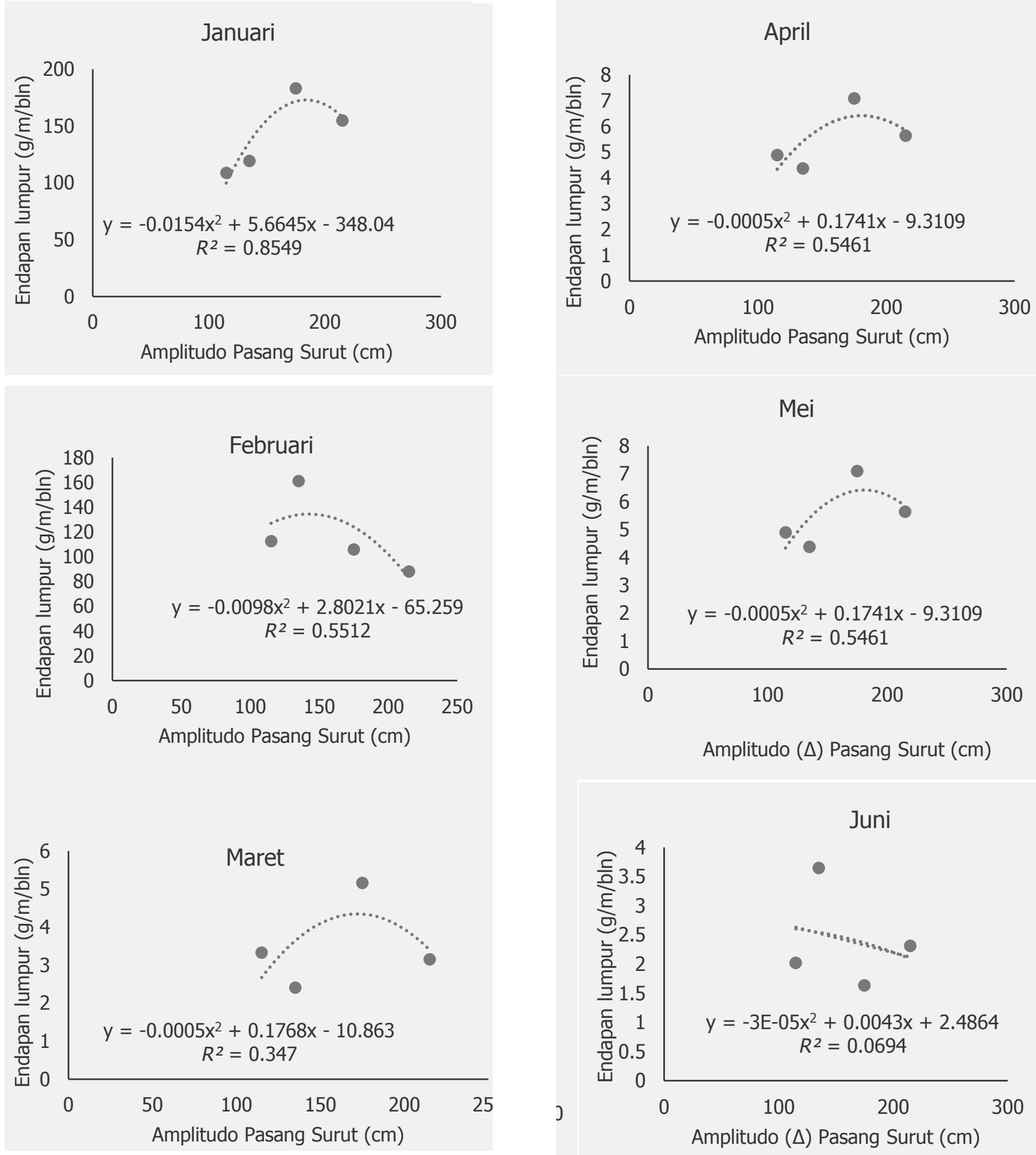

Gambar 8. Hubungan amplitodu $(\Delta)$ pasang surut dengan endapan lumpur secara vertikal Perbulan (Januari - Juni) 


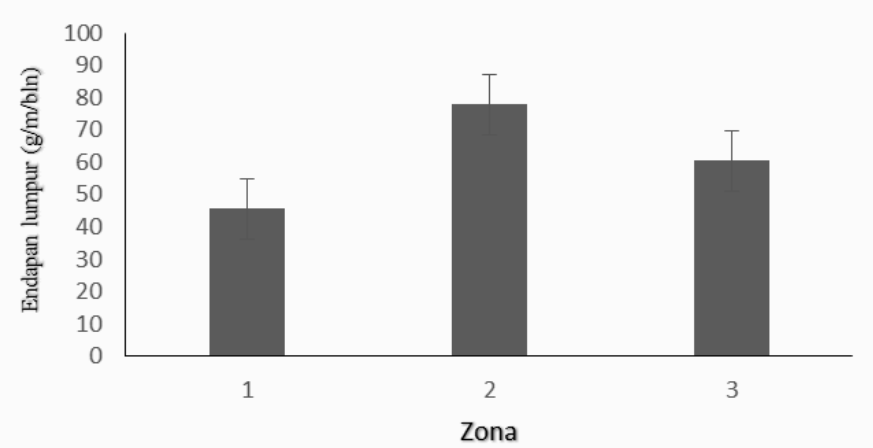

Gambar 9. Perbandingan antar zona $\Delta$ pasang surut dengan rata rata endapan lumpur per bulan secara horizontal

pancar, sebagian besar menunjukkan pola hubungan parabola (kuadratik) dengan R2 berkisar 0,8 - 0,5 kecuali pada bulan Juni. Jika direrata nilai korelasinya (R2) menjadi lebih tinggi dengan persamaan korelasi $y=-, 5052 x^{2}+21,137 x+26,563$ dan $R^{2}=0,9971$. Hal ini menunjukkan bahwa nilai amplitudo pasang surut sangat mempengaruhi endapan lumpur.

Pengaruh amplitodu pasang surut secara horizontal digambarkan dalam bentuk diagram batang (Gambar
9). Pada Tabel 2, terlihat zona II dan III yang $\Delta$ pasang surutnya vertikal (Gambar 5) $100-150 \mathrm{~cm}$ dan 150 $200 \mathrm{~cm}$, rata-rata lumpur yang terendapkan 51,6 dan $49,08 \mathrm{~g} / \mathrm{m}^{2} /$ bulan atau 306,95 dan $294,49 \mathrm{~g} / \mathrm{m}^{2} / 6$ bulan. Nilai-nilai ini lebih tinggi jika dibandingkan dengan zona I dan Zona IV yang hanya 43,08 dan 39,14 g/ $/ \mathrm{m}^{2} /$ bulan.

Secara horizontal (sejajar dengan laut) amplitodu $(\Delta)$ pasang dibagi menjadi 4 zona (Gambar 4), namun dalam penelitian ini hanya tiga zona. Selain itu, pada zona IV sebagian besar sudah tidak terluapi air pasang surut kerena termasuk tipe luapan C dan D (Widjaja, 1986). Tabel 3 menunjukkan bahwa bagian tengah atau zona II memiliki kadar lumpur $77,78 \mathrm{~g} / \mathrm{m}^{2} /$ bulan lebih tinggi dibanding zona I yang hanya $45,62 \mathrm{~g} / \mathrm{m}^{2} /$ bulan maupun Zona III 60,39, g/ $\mathrm{m}^{2} /$ bulan. Hal ini disebabkan pada zona II amplitodu pasang surutnya tidak terlalu tinggi dan tidak terlalu rendah $(100-120 \mathrm{~cm})$, cendrung bersifat kuadratik $\left(R^{2}\right)$ seperti pola vertikal. Akibatnya banyak lumpur yang mengendap pada zona tersebut dibandingkan pada zona I yang amplitodu pasang surutnya lebih tinggi dan zona III yang amplitodunya lebih kecil, sehingga daerah ini menjadi kawasan pertanian yang subur.

Tabel 2. Sebaran lumpur pada zona I - IV secara vertikal pada saluran primer di lahan sawah pasang surut kawasan Sungai Barito

\begin{tabular}{lrrrrrrr}
\hline \multicolumn{1}{c}{ Bulan } & $\begin{array}{c}\text { Zona I } \\
\left(\mathrm{g} / \mathrm{m}^{2} / \mathrm{bln}\right)\end{array}$ & $\begin{array}{c}\text { Zona II } \\
\left(\mathrm{g} / \mathrm{m}^{2} / \mathrm{bln}\right)\end{array}$ & $\begin{array}{c}\text { Zona III } \\
\left(\mathrm{g} / \mathrm{m}^{2} / \mathrm{bln}\right)\end{array}$ & $\begin{array}{c}\text { Zona IV } \\
\left(\mathrm{g} / \mathrm{m}^{2} / \mathrm{bln}\right)\end{array}$ & $\begin{array}{r}\text { Total } \\
\left(\mathrm{g} / \mathrm{m}^{2} / \mathrm{bln}\right)\end{array}$ & $\begin{array}{r}\text { Rata-rata } \\
\left(\mathrm{g} / \mathrm{m}^{2} / \mathrm{bln}\right)\end{array}$ & SD \\
\hline Januari & 154,62 & 182,87 & 119,18 & 108,71 & 565,38 & 141,34 & 31,2 \\
Februari & 88,14 & 105,87 & 161,04 & 112,45 & 467,49 & 116,87 & 1,2 \\
Maret & 3,15 & 5,16 & 2,41 & 3,33 & 14,05 & 3,51 & 1,2 \\
April & 5,64 & 7,09 & 4,37 & 4,89 & 21,99 & 5,50 & 0,5 \\
Mei & 4,61 & 4,33 & 3,85 & 3,45 & 16,25 & 4,06 & 0,9 \\
Juni & 2,31 & 1,63 & 3,64 & 2,02 & 9,60 & 2,40 & 33,1 \\
Total & 258,48 & 306,95 & 294,49 & 234,84 & 1094,76 & 273,69 & 5,5 \\
Rata-rata & 43,08 & 51,16 & 49,08 & 39,14 & 182,46 & 45,62 & 33,9 \\
\hline
\end{tabular}

Tabel 3. Sebaran lumpur pada zona I - III cara horizontal dari muara laut ke hulu sejauh $60 \mathrm{~km} \mathrm{di}$ lahan sawah pasang surut kawasan Sungai Barito

\begin{tabular}{lcccccc}
\hline \multicolumn{1}{c}{ Bulan } & $\begin{array}{c}\text { Zona I } \\
\left(\mathrm{g} / \mathrm{m}^{2} / \mathrm{bln}\right)\end{array}$ & $\begin{array}{c}\text { Zona II } \\
\left(\mathrm{g} / \mathrm{m}^{2} / \mathrm{bln}\right)\end{array}$ & $\begin{array}{c}\text { Zona III } \\
\left(\mathrm{g} / \mathrm{m}^{2} / \mathrm{bln}\right)\end{array}$ & $\begin{array}{c}\text { Total } \\
\left(\mathrm{g} / \mathrm{m}^{2} / \mathrm{bln}\right)\end{array}$ & $\begin{array}{c}\text { Rata-rata } \\
\left(\mathrm{g} / \mathrm{m}^{2} / \mathrm{bln}\right)\end{array}$ & SD \\
\hline Januari & 141,34 & 227,49 & 60,01 & 428,85 & 142,95 & 82,6 \\
Februari & 116,87 & 207,55 & 281,82 & 606,24 & 202,08 & 4,5 \\
Maret & 3,51 & 11,43 & 3,64 & 18,59 & 6,20 & 2,4 \\
April & 5,50 & 10,29 & 7,21 & 23,00 & 7,67 & 1,9 \\
Mei & 4,06 & 6,58 & 7,69 & 18,33 & 6,11 & 0,7 \\
Juni & 2,40 & 3,33 & 1,95 & 7,68 & 2,56 & 96,6 \\
Total & 273,69 & 466,66 & 362,32 & 1102,67 & 367,56 & 16,1 \\
Rata-rata & 45,62 & 77,78 & 60,39 & 183,78 & 61,26 & 83,8 \\
\hline
\end{tabular}


Hubungan antara amplitodu pasang surut bersifat kuadratik. Hal ini menujukkan bahwa nilai amplitodu pasang surut ada nilai optimunnya. Perbedaan antara pasang maksimum dan surut maksimum yang tinggi ini juga menyebabkan arus air bergerak cepat membawa endapan, sehingga total endapan tersuspensi juga meningkat.

Arus yang lebih tinggi juga mengandung energi yang kuat (Wahab dkk., 2016). Akibatnya lumpur yang sudah masuk ke lahan belum sempat mengendap sempurna, masih berupa suspense dan terbawa lagi keluar hanya tertinggal sebagian. Sebaliknya, pada $(\Delta)$ amplitodu yang nilainya rendah, lumpur yang terendapkan di lahan juga sedikit. Hal ini diduga air yang masuk ke lahan dengan arus yang lemah sehingga suspensi lumpur yang terendapkan juga sedikit.

Pada titik optimum dengan amplitudo pasang surut $(\Delta)$ yang sedang, air masih bisa masuk dengan arus yang sedang cukup untuk membawa suspensi lumpur. Namun karena selisih antara pasang maksimum dan surut terendah tidak terlalu besar, sehingga lumpur yang tersuspensi dapat mengendap sempurna dan tidak terbawa keluar kembali pada saat surut.

\section{Pengaruh Amplitudo Pasang Surut Harian Air terhadap Sebaran Lumpur}

Hubungan amplitudo pasang surut air harian terhadap lumpur total perbulan diperlihatkan Pada Gambar 10 dan 11.

Dari Gambar 10 dan 11 terlihat bahwa fluktuasi sebaran lumpur di lahan sawah. Fluktuasi sebaran lumpur tergantung musim. Pada bulan Januari dan Februari kandungan lumpur tertinggi pada semua zona pengamatan. Hal ini diduga pada saat awal musim hujan banyak sekali lumpur hasil erosi yang terbawa air sungai kemudian diendapkan di sawah, seperti yang

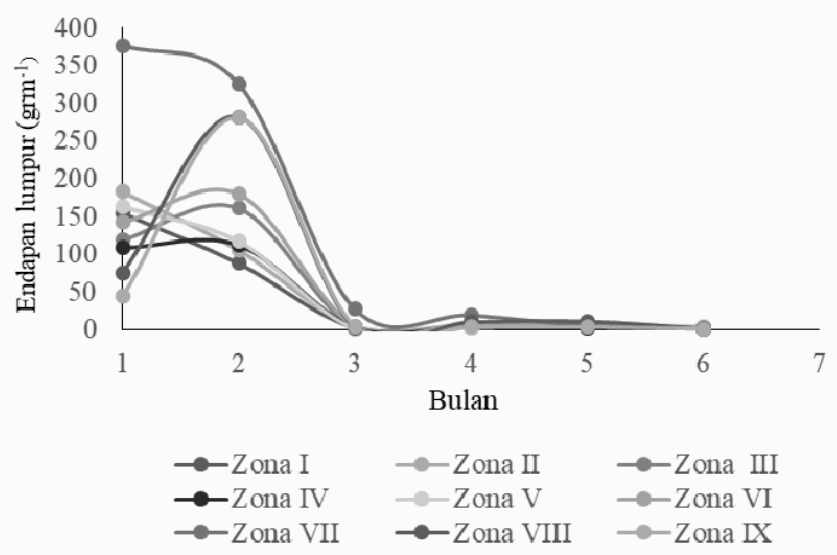

Gambar 10. Dinamika endapan lumpur selama 6 bulan pada 9 zona $\Delta$ pasang surut di kawasan sawah Sungai Barito

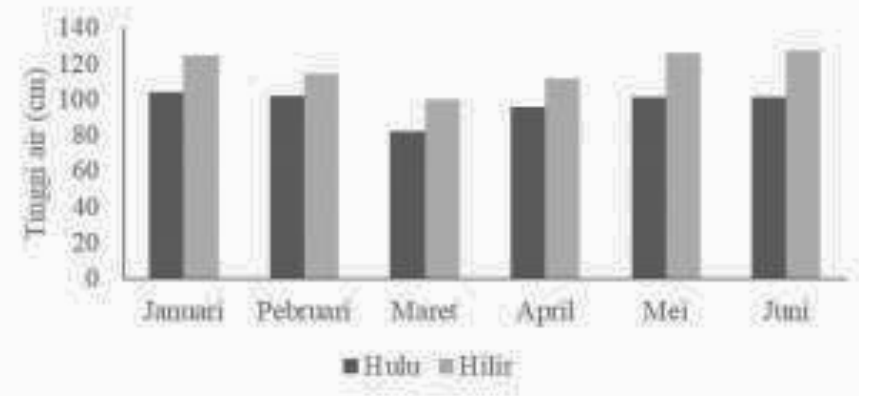

Gambar 11. Dinamika $\Delta$ pasang surut selama 6 bulan pada dua lokasi pengamatan di Sungai Barito

terjadi sub DAS Serang bahwa sedimen meningkat pada bulan April, seiring terjadi peningkatan curah hujan, debit dan tinggi muka air (Mahmud dkk., 2009).

Penurunan curah hujan pada bulan Maret juga mempengaruhi jumlah lumpur yang di endapkan di lahan secara drastis, diikuti dengan menurunnya $\Delta$ pasang surut, namun pada bulan April, curah hujan kembali meningkat dan diikuti pula dengan meningkatnya $\Delta$ pasang surut, tetapi jumlah lumpur yang di endapkan di lapangan terus berkurang sampai bulan Juni. Hal ini diduga kuat lumpur yang berasal dari hulu sudah sangat berkurang, dan air sungai juga sudah tidak keruh lagi. Selain itu, dorongan arus dari hulu sungai tidak terlalu besar, berupa gaya internal yang mempengaruhi arus seperti perbedaan densitas air laut, gradien tekanan mendatar dan up welling (Try dkk., 2017). Karena sudah memasuki musim kemarau sehingga air hanya dapat masuk ke lahan pada saat pasang besar saja. Selain itu, lumpur yang tersuspensi juga berkurang sehingga yang diendapkan di lahan sawah pun juga sudah sangat berkurang.

\section{KESIMPULAN}

Distribusi spasial zona lumpur di lahan pasang surut bervariasi dan sangat dipengaruhi oleh nilai amplitudo $(\Delta)$ pasang surut. Hubungan (korelasi) bersifat kudratik $\left(R^{2}\right)$, dengan nilai amplitudo $(\Delta)$ pasang surut sebesar 100 - $200 \mathrm{~cm}$ secara horizontal dan 120 $150 \mathrm{~cm}$ secara vertikal. Kadar lumpur tertinggi berada pada zona VI, dibandingkan 8 zona lainya, sehingga sangat mendukung untuk usaha pertanian terutama tanaman padi di lahan pasang surut. Jumlah endapan lumpur selain dipengaruhi amplitudo $(\Delta)$ pasang surut, juga oleh musim kemarau dan penghujan. Pada awal musim hujan sungai banyak membawa material lumpur dari hulu sungai, namun sebarannya tetap ditentukan oleh nilai amplitudo $(\Delta)$ pasang surut. 


\section{UCAPAN TERIMA KASIH}

Ucapan terimakasih disampaikan kepada Badan Litbangtan Kementerian Pertanian yang telah memberi bantuan dana dalam penelitian ini. Ucapan terimakasih juga disampaikan kepada semua pihak yang berperan dan terkait dalam kegiatan penelitian ini. Ucapan terima kasih dapat juga disampaikan kepada pihak-pihak yang membantu pelaksanaan penelitian ini terutama teknisi Yayasan Cahaya Ar Rahman yang selalu mendampingi dalam pengambilan data dan para petani yang ada di Kecamatan Tabunganen, Tamban, Mekarsari, Anjir, Bambangin dan Barambai, yang membantu pengamatan dan pengamanan alat di lapangan.

\section{DAFTAR PUSTAKA}

BPS, 2017. Kabupaten Barito Kuala. Produksi Padi Sawah Menurut Kecamatan di Kabupaten Barito Kuala, 2011- 20015. (https://baritokualakab.bps.go.id/ dynamictable/2017/01/17 /864/produksi-padisawah-menurut-kecamatan-di-kabupaten-baritokuala-2011-2015.html).

Franco, A. D. S., 1966, Tides.Fundamentals, prediction and analysis, International Hydrographic Office, Monaco.

Hariyanto, T., Krisna, T. C., \& Pribadi, C. B. (2017). Development of Total Suspended Sediment Model using Landsat-8 OLI and In-situ Data at the Surabaya Coast, East Java, Indonesia, 49(1), 73-79.

Hydrographer of the Nurry 1969, Tides and tidal streams, Admiralty of Hydrographic Surveyimg, Taunton. Hydrographer of the Nurry, 1969, Tides and tidal streams, Admiralty of Hydrographic Surveyimg, Taunton.

Hydrographic Hydrographic Services, 1987, Physical oceanographic survey course, Group Training Course In Hydrographic Services, Tokyo.

Klasifikasi, M. D. A. N., Hardjowigeno, S., Subagyo, H., \& Rayes, M. L. (1950). 1. morfologi dan klasifikasi tanah sawah, 1-28.
Mahmud, Joko H. Susanto. (2009). Penilaian Status Daerah Aliran Sungai ( Studi Kasus Sub Das Serang ), Journal AGRITECH, Vol. 29, No. 4 November 2009

Marchuk, G. L, Kagan, B. A., 1983, Dynamics of ocean tides, Kluwer Academic Publizshers, Dordrecht.

Noor, M. 2004. Lahan Rawa Sifat dan Pengelolaan Tanah Bermasalah Sulfat Masam. Divis Buku Perguruan Tinggi. Raja Grafindo Persada. Jakarta.

Pariwono, J., 1985, Australian cooperative programmes in marine sciences: tides and tidal phenontena in the ASEAN region, Fl inders University, Flinders).

Shamsuddin, J., S. Muhrizal, I, Fauziah and E Van Ranst. 2004. A.laboratory study of pyrite oxidation in acid sulfate solils. Communication in Soil Science and Plant Analysis.

Subagyo, H. 2006. Karakteristik dan Pemgelolaan Lahan Rawa. Lahan Rawa Pasang Surut. Balai Besar Penelitian dan Pengembangan Sumberdaya Lahan Pertanian. Badan Penelitian dan Pengembangan Pertanian. Departemen Pertanian. Jakarta. ISBN 979-9474-52-3

Sudana, W. (2005). Potensi dan prospek lahan rawa sebagai sumber produksi pertanian. Analisis Kebijakan Pertanian, 3, 141-151.

Suriadikarta, uriadikarta, D. A. (2012). Teknologi Pengelolaan Lahan Rawa Berkelanjutan : Studi kasus Kawasan EX PLG Kalimantan Tengah. (Technology for Sustainable Management of Tidal Swampy Areas: Case Study in former PLG in Central Kalimantan Povince) Journal Sumberdaya Lahan Vol. 6 No. 1, Juli 2012.

Thuy, N. N., \& Anh, H. H. (2015). Vulnerability of Rice Production in Mekong River Delta under Impacts from Floods, Salinity and Climate Change, 5(4), 272-279.

Try Al Tanto, Ulung Jantama Wisha, Gunardi Kusumah, Widodo S Pranowo, Semeidi Husrin, \& Aprizon Putra. (2017). Characteristics of Sea Current in Benoa Bay Waters - Bali. Ilmiah Geomatika, 23(1), 37-48. https:// doi.org/10.24895/JIG.2017.23-1.\%25x

Unesco, 1994. Manual on sea level measurement and interpretation. Volume I-Basic procedures, Intergovermental Oceanographic Commission, Paris. 